\title{
A survey of Salmonella spp and Campylobacter spp in dairy goat faeces and bulk tank milk in the Murcia region of Spain
}

\author{
Carmen Cortés', Ricardo de la Fuente', Antonio Contreras², Antonio Sánchez², Juan C. Corrales², Susana Martínez' and José A. Orden' \\ ' Departamento de Sanidad Animal, Facultad de Veterinaria, Universidad Complutense, 28040 Madrid, Spain \\ ${ }^{2}$ Departamento de Sanidad Animal, Facultad de Veterinaria, Universidad de Murcia, 3007I Murcia, Spain
}

This study was designed to investigate the occurrence of Salmonella spp and Campylobacter spp in faeces samples from 222 healthy Murciano-Granadina dairy goats reared on 12 farms in Spain and in samples of bulk tank milk from II of those herds. Neither Salmonella spp nor Campylobacter spp were isolated from any of the samples. Our results suggest that, under the management practices applied to this breed in Spain, Murciano-Granadina goats are not likely to be a significant reservoir for these food-borne pathogens.

Irish Veterinary Journal

Volume 59 (7) 391-393, 2006

Keywords: Dairy goats, Salmonella, Campylobacter.

\begin{abstract}
Introduction
Salmonella spp and Campylobacter spp are important food-borne pathogens and the consumption of goat's meat (Pépin et al., 1997) or unpasteurised goat's milk and cheese have been associated with some outbreaks of infection in humans (Harris et al., 1987; Rampling, 1998). Both Salmonella spp and Campylobacter spp have been associated with disease in goats (Prescott and Bruin-Mosch, 198I; Smith and Sherman, 1994) but they are also found in animals that show no signs of clinical illness. In dairy cows, the main source of contamination of bulk tank milk is faecal shedding of these pathogens by asymptomatic animals and this has led to the proposal of on-farm management interventions to enhance the safety of dairy products (Ruegg, 2003). As opposed to the situation for poultry, pigs, cattle and sheep, very few largescale epidemiological studies have been undertaken on goats as potential faecal carriers of Salmonella spp and Campylobacter spp. To our knowledge, such a study has not been performed in Spain.
\end{abstract}

The objective of this investigation was to check for the presence of faecal carriers of Salmonella spp and Campylobacter spp among healthy Murciano-Granadina goats on 12 Spanish farms. The bulk tank milk of these farms was also tested for both pathogens.

\section{Materials and methods}

The study was conducted over a three-month period from May to July 2003 on 12 Murciano-Granadina goat herds reared on farms of the Asociación Española de Criadores de la Cabra MurcianoGranadina (ACRIMUR), in the Murcia (southeastern) region of Spain. This organisation is responsible for the national breeding programme

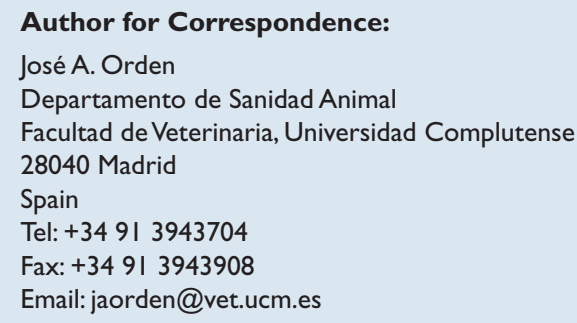

for this particular breed. There was no movement of animals or personnel between the farms studied. The herds ranged in size from I 20 to 450 lactating goats, machine-milked once daily. In all herds, the milking parlour was separated from the housing area and the milk was conducted by milk pipeline to the receiver jar connected by milk delivery line to the refrigeration tank located in a separate room. Milking routine did not include prior udder preparation or milkingunit sanitation between goats and post-dipping teat disinfection was carried out using iodine solution by dipper cup or teat sprayer. After milking, the milking equipment was cleaned according to the standard protocols provided by the manufacturer. Animals were periodically immunised against enzootic abortion, contagious agalactia and enterotoxaemia. All the herds were classified free of brucellosis and tuberculosis and were under a mastitis control programme based on monitoring the somatic cell count and selective antibiotic dry therapy. The practice of artificial rearing, in which kids are withdrawn after parturition and fed pasteurised colostrum and milk replacer, was implemented in eight of the herds. Nine of the 12 herds were allocated indoor space with free access to an open yard and were fed a balanced total mixed ration and alfalfa hay. The other three herds were given a similar diet but had access to pasture (three hours per day).

On the day of sampling, the farm owners declared that their herds had not had abortions nor were any of their animals currently suffering from digestive disorders. Healthy animals were randomly selected and 222 faeces samples were collected. Animals of up to four weeks of age were classified as goat kids $(n=40)$, those between one and nine months old were classified as replacement animals $(n=8 I)$ and those older than nine months were classified as adults $(n=|0|)$. Faeces were obtained directly from the rectum using swabs and transferred to tubes containing Amies transport medium (Deltalab, Barcelona, Spain) or Cary Blair transport medium (Deltalab). Additionally, one sample of bulk tank milk was taken from each of the II herds. Milk samples were collected into sterile containers $(30 \mathrm{ml})$ after agitation 
of the bulk tank milk at $5^{\circ} \mathrm{C}$. On the day of sampling, all samples were submitted to the laboratory by express mail in refrigerated containers and they were processed within 24 hours of reception.

The procedures for the isolation of Salmonella species included enrichment of swabs with Amies transport medium and enrichment of milk samples in tetrathionate broth (Difco, Becton Dickinson, Sparks, Maryland, USA), supplemented with $40 \mathrm{mg} / \mathrm{ml}$ novobiocin (Sigma, Sigma-Aldrich, St. Louis, Missouri, USA). After 24 hours of incubation at $37^{\circ} \mathrm{C}$, samples were plated onto XLD agar (Difco), and they were incubated for 24 hours at $37^{\circ} \mathrm{C}$.

The procedures for the isolation of Campylobacter species included enrichment of swabs with Cary Blair transport medium and enrichment of milk samples in Bolton selective enrichment broth (Oxoid, Basingstoke, UK). The broths were incubated at $37^{\circ} \mathrm{C}$ for 48 hours in a microaerophilic atmosphere achieved using commercial gas-generating kits (CampyGen, Oxoid). Following incubation, samples were plated on Karmali selective medium (Oxoid) and AbeytaHunt-Bark agar (Hunt et al., 200I) and they were incubated in a microaerophilic atmosphere at $37^{\circ} \mathrm{C}$ for 48 hours.

\section{Results and discussion}

Neither Salmonella nor Campylobacter spp were recovered from the faeces samples or milk samples. In Italy, Cortesi et al. (1984) evaluated Salmonella carriage in $\mathbf{4 0}$ healthy goat kids at slaughter, and recovered Salmonella from the intestinal contents of only one animal. However, in Nigeria, Adesiyun et al. (1988) isolated Salmonella spp from intestinal contents, bile and mesenteric lymph nodes in 19 (9.5\%) of 200 slaughtered goats, although these bacteria could be isolated from the intestinal contents of only five (2.5\%) of the animals studied.

The carriage rates reported in those studies on intestinal contents of animals at slaughter contrast with the null rate in our survey; perhaps, the difference in procedure for the collection of the samples may have been a significant contributory factor to that contrast. Samples taken at slaughter can lead to overestimates of normal prevalence, since it has been shown that the stress of transportation and of food withdrawal experienced by animals before slaughter increases the number of shedders of Salmonella spp among these animals (Ekperigin and Nagaraja, 1998). The overall impression from the three studies is that Salmonella spp are rarely isolated from the intestinal contents or faeces of healthy goats.

Here, failure to find Campylobacter spp in the faeces of any of the healthy goats is consistent with the results of an earlier study in Norway in which neither Campylobacter jejuni nor Campylobacter coli was found in any of the rectal swabs and stool specimens of the goats examined (Rosef et al., 1983). Nevertheless, other investigators have reported the isolation of Campylobacter spp from rectal swabs or faeces samples of healthy goats, although rates have been highly variable. In Canada, Prescott and Bruin-Mosch (198I) were able to identify C. jejuni in $2.7 \%$ of the animals studied. Turkson et al. (1988), in Kenya, found Campylobacter species in $6.3 \%$ of the goats sampled, and Abrahams et al. (1990) in Ghana detected $C$. jejuni, but not $C$. coli, in a high proportion (33.3\%) of the goats tested. These different carriage rates could be attributable to contact of goats with other animal species. Thus, Jiwa et al. (1994) explored the prevalence of Campylobacter spp in healthy goats kept under various management systems in Tanzania and observed that goats kept away from other farm animals, irrespective of whether the management system was good or poor, were negative for Campylobacter spp. However, three out of 20 goats confined to a small area, but in contact with $C$. colipositive pigs and chickens became infected with $C$. coli. The results of that study suggest that goats are not natural hosts of Campylobacter spp and that pigs and poultry may be a source of infection. Hence, the lack of faecal carriers of Campylobacter spp reported here could be explained by the fact that the goats were not in contact with other animals, together with other factors such as the breed of goat and the environmental conditions.

The failure to isolate Salmonella spp or Campylobacter spp from the bulk tank milk of the herds examined here does not provide evidence of contamination by faecal carriers, which are generally the main source of these pathogens in raw milk. This finding is in agreement with those obtained by other authors, who failed to detect these bacteria in unpasteurised milk from goats (Jiwa et al., 1994; Little and de Louvois, 1999; Foschino et al., 2002; Morgan et al., 2003; Muehlherr et al., 2003). In cow bulk tank milk samples, several studies have reported a frequency of isolation that ranged between $0.4 \%$ and $12.3 \%$ for $C$. jejuni and between $0.2 \%$ and $8.9 \%$ for Salmonella. The results so far obtained for the milk of healthy goats suggest that goat's milk is a safer product than cow's milk. However, further studies are necessary to evaluate the risk of these pathogens contaminating milk in the bulk tank whenever there are clinical cases in the herd.

In conclusion, the healthy Murciano-Granadina dairy goats examined were free of Salmonella spp and Campylobacter spp. This suggests that, under the management practices applied to this breed in Spain, there is a very low risk that Murciano-Granadina goats will serve as a reservoir for these food-borne pathogens.

\section{Acknowledgements}

This work was supported by a grant from the Instituto de Salud Carlos III (grant FIS G03/025). We thank D. Jara and F.J. García for technical assistance.

\section{References}

Abrahams, C.A., Agbodaze, D., Nakano, T., Afari, E.A. and Longmatey, H.E.K. (1990). Prevalence and antibiogram of Campylobacter jejuni in domestic animals in rural Ghana. Archives of Environmental Health 45: 59-62.

Adesiuyn, A.A., Dasuki, M.O. and Ibrahim, G.A. (1988). Occurrence and antibiograms of salmonellae isolated from slaughter sheep and goats in Zaria; Nigeria. Israel Journal of Veterinary Medicine 44: 248-255.

Cortesi, M.L., Brillante, M. and De Giovanni, F. (1984). Salmonella carriage by apparently healthy slaughter sheep and goats. Archivo Veterinario Italiano 35: 258-26I.

Ekperigin, H.E. and Nagaraja, K.V. (1998). Salmonella. Veterinary Clinics of North America: Food Animal Practice 14: 17-29.

Foschino, R., Invernizzi, A., Barucco, R. and Stradiotto, K. (2002). Microbial composition, including the incidence of pathogens, of goat milk from the Bergamo region of Italy during a lactation year. Journal of Dairy Research 69: 213-225.

Harris, N.V., Kimball, T.J., Bennett, P., Johnson, Y., Wakely, D. and Nolan, C.M. (1987). Campylobacter jejuni enteritis associated 
with raw goat's milk. American Journal of Epidemiology I 26: I79-I86.

Hunt, J.M., Abeyta, C. and Tran, T. (200I). Campylobacter. IN: Bacteriological Analytical Manual Online. Chapter 7. College Park, Maryland: U.S. Food and Drug Administration. Center for Food Safety and Applied Nutrition. [Online].Available from: <http:// www.cfsan.fda. gov/ ebam/bam-toc.htlm>

Jiwa, S.F.H., Kazwala, R.R. and Namahungu, E. (1994). Prevalence of Campylobacter spp. in clinically normal goats kept under various management systems in urban Tanzania. Small Ruminant Research I5 97-100.

Little, C.L. and de Louvois, J. (1999). Health risks associated with unpasteurized goat's and ewe's milk on retail sale in England and Wales. A PHLS dairy products working group study. Epidemiology and Infection I 22: 403-408.

Morgan, F., Massouras, T., Barbosa, M., Roseiro, L., Ravasco, F., Kandarakis, I., Bonnin, V., Fistakoris, M., Anifantakis, E., Jaubert, G. and Raynal-Ljutovac, K. (2003). Characteristics of goat milk collected from small and medium enterprises in Greece, Portugal and France. Small Ruminant Research 47: 39-49.

Muehlherr, J.E., Zweifel, C., Corti, S., Blanco, J.E. and Stephan, R. (2003). Microbial quality of raw goat's and ewe's bulk-tank milk in Switzerland. Journal of Dairy Science 86: 3849-3856.

Pépin, M., Russo, P. and Pardon, P. (1997). Public health hazards from small ruminant meat products in Europe. Revue Scientifique et Technique (International Office of Epizootics) 16:415-425.

Prescott, J.F. and Bruin-Mosch, C.W. (198I). Carriage of Campylobacter jejuni in healthy and diarrheic animals. American Journal of Veterinary Research 42: 164-165.

Rampling, A. (1998). The microbiology of milk and milk products. IN: Topley and Wilson's Microbiology and Microbial Infections. Volume 2 , Chapter 16. Ninth edition. London:Arnold.

Rosef, O., Gondrosen, B., Kapperud, G. and Underdal, B. (1983). Isolation and characterization of Campylobacter jejuni and Campylobacter coli from domestic and wild mammals in Norway. Applied and Environmental Microbiology 46: 855-859.

Ruegg, P.L. (2003). Practical food safety interventions for dairy production. Journal of Dairy Science $\mathbf{8 6}$ (Electronic Supplement): EI-E9.

Smith, M.C. and Sherman, D.M. (1994). Goat Medicine. Pennsylvania: Lea and Febiger.

Turkson, P.K., Lindqvist, K.J. and Kapperud, G. (1988). Isolation of Campylobacter spp and Yersinia enterocolitica from domestic animals and humans patients in Kenya. Acta Pathologica, Microbiologica, et Immunologica Scandinavica 96: |4|-|46. 